\title{
Smoking reduction did not promote future smoking cessation in a general population
}

\author{
Charlotta Pisinger $^{{ }^{*}}$, Mette Aadahl ${ }^{1}$, Ulla Toft ${ }^{1}$, Torben Jørgensen ${ }^{1,2}$ \\ ${ }^{1}$ Research Centre for Prevention and Health, Glostrup University Hospital, The Capital Region of Denmark, Copenhagen, Denmark; \\ *Corresponding Author: chpi@regionh.dk \\ ${ }^{2}$ Faculty of Health Science, Copenhagen University, Copenhagen, Denmark.
}

Received 21 August 2011; revised 28 September 2011; accepted 14 October 2011.

\section{ABSTRACT}

Introduction: Smoking reduction (SR) has been introduced as a strategy for smokers who are unwilling or unable to quit. We wanted to investi tigate whether SR at one-year follow-up increased the probability of abstinence from smoking at three and five-year follow-up. Methods: we included a random sample from a general population, the Inter99 study, Copenhagen, Denmark. A total of 1975 participants were daily smokers (from both the intervention and the control group) with information on tobacco consumption at both baseline and one-year follow-up (year 1999 to 2001). Of these, 112 had reduced their tobacco consumption substantially, by mi-

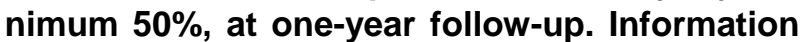
on tobacco consumption and smoking status was available on 1441 and 1308 participants at three-year and five-year follow-up, respectively. Outcome was self-reported point abstinence at three and five-year follow-up. Logistic regression analyses were adjusted for confounders. Results: One out of five smokers (20.5\%) had maintained their reduced tobacco consumption at five-year follow-up. About twice as many reducers as non-reducers reported that they had tried to quit since baseline $(p<0.05)$. In adjusted logistic regression analyses we found no association between SR at one-year follow- up and being point abstinent at three-year (OR: 0.57 ; $\mathrm{Cl}$ : $0.28-1.15$ ) or five-year follow-up (OR: 1.08 ; Cl: 0.56 - 2.09). Conclusions: Our study, including smokers from a general population found no association between substantial SR and future smoking cessation at three- and five-year follow-up. No studies so far have reported that SR undermines smoking cessation, but it is still controversial whether SR significantly increases future smoking cessation.

Keywords: Smoking Cessation; Smoking

Reduction; Tobacco Consumption

\section{INTRODUCTION}

Smoking is still the leading preventable cause of death in the western countries [1,2]. Smoking reduction (SR), i.e. a decrease in number of cigarettes smoked daily, has been introduced as a strategy for the majority of smokers who are not motivated to quit in near future or unable to quit. Smoking reduction, also called controlled smoking or harm reduction is a controversial area. A burning question is how SR relates to success of quit attempts in later years. Does SR increase or decrease the probability of future abstinence? Several papers have tried to answer this question [3-20] but we lack more knowledge from an unselected sample of smokers from a general population. This is of great importance before implementing SR as a population-based strategy.

Previous studies can be split into three types: a) Randomised controlled trials (RCT) testing the efficacy of nicotine replacement therapy (NRT) to help reluctant smokers reduce their tobacco consumption [4,7,9,11-13]. All smokers included were smokers willing to reduce and instructed to reduce. Only one study compared reducers with non-reducers when reporting future abstinence [13]. The other trials compared smokers receiving NRT with smokers receiving placebo. b) Papers reporting on self-selected reducers $[3,6,8,14,16-20]$. Smokers in these studies were not encouraged to reduce. Some studies have been population-based surveys reporting spontaneous changes in tobacco consumption $[6,14,16$, 18-20]; others have reported results from smoking cessation trials $[3,8,17,20]$. c) Finally, a few RCTs have randomised smokers reluctant to quit in near future to reduction with assistance versus no treatment $[5,10,15]$. Many of the studies were in selected smokers (female 
prisoners, young women, twins, old, coloured, heavy or light smokers or smokers with chronic diseases) [3,8, 13-18]. Others reported old data [14] or were at risk of recall bias $[17,19]$. Even though about half of the studies [7,11-14,17-20] indicate that smoking reduction/substantial reduction increases the rate of future smoking cessation the subject is still controversial.

In a large Danish population-based intervention study, Inter99, we found that SR was feasible and that it increased motivation to quit at one-year follow-up [21]. The study is not a randomized test of reduction, but rather a prospective examination of self-selected reducers vs. non-reducers.

The aim of this paper is to investigate whether substantial reduction in daily tobacco consumption $(50 \%$ or more) at one-year follow-up increased the probability of abstinence from smoking at three and five-year follow-up. This will be done in a large sample of daily smokers from a general population.

\section{METHODS}

The Inter 99 study. Inter99 is a population-based intervention study initiated in March 1999 and ended in April 2006. The study design is described in detail elsewhere $[22,23]$. The aim of the study was to prevent cardiovascular disease by non-pharmacological intervention. The study was performed at the Research Centre for Prevention and Health [24], Glostrup University Hospital, Copenhagen, Denmark, and was approved by The Copenhagen County Ethical Committee (KA 98155) and the National Board of Health. Written informed consent was obtained from all participants. The study was registered in the Clinical Trials.gov (NCT00289237). The study population $(\mathrm{N}=61,301)$ comprised all individuals in specific age-groups (30 to 60 years) from a defined area of Copenhagen. From this study population three age- and sex-stratified random samples were drawn: two for the intervention groups (a total of 13,016: a high intensity intervention group $\mathrm{A}(\mathrm{N}=11,708)$, and a low intensity intervention group $\mathrm{B}(\mathrm{N}=1308))$; and one for the control group $\mathrm{C}(\mathrm{N}=5246)$. The groups were prerandomised. Baseline participation rates were $52.5 \%$ in the intervention group and $63.1 \%$ in the control group.

Persons included in this paper. At baseline (year 1999 to 2001) a total of 3684 persons included in the intervention $(\mathrm{N}=2408)$ and control groups $(\mathrm{N}=1,276)$ stated to be daily smokers and 3663 (99.4\%) gave information on their daily tobacco consumption. Out of these, $2385(65.1 \%)$ reported their smoking status at one-year follow-up and 1975 (53.9\%) were daily smokers with information on tobacco consumption at both baseline and one-year follow-up (group AB: $\mathrm{N}=1086$ and group $\mathrm{C}: \mathrm{N}=889$ ). A total of 112 daily smokers (89 in the intervention groups and 23 in the control group) had reduced their tobacco consumption at one-year follow-up. Information on daily tobacco consumption was available on 1441 (73\%) and 1308 (66\%) participants, at three-year and five-year follow-up, respectively, of those who were daily smokers at baseline.

Smoking reduction intervention. The primary focus of the intervention was smoking cessation and all smokers were in a lifestyle consultation with a health professional strongly encouraged to quit. Smokers unwilling to, or not ready to quit were encouraged to think more about the harm and disadvantages of smoking, and to reduce their tobacco consumption as much as possible. The aim was to quit "one day". Additionally, at baseline, reluctant daily smokers in intervention group A were offered participation in group-based SR intervention and $2 \%$ of them accepted and attended the groups. The smoking reduction intervention has been described in detail elsewhere[21].

Definition of smoking reduction. We measured "grams of tobacco" in the following way: 1 cigarette $=1$ gram, 1 gram pipe tobacco $=1$ gram, 1 cheroot $=3$ grams, 1 cigar $=5$ grams. Smoking reduction was defined as minimum $50 \%$ reduction of daily tobacco consumption from baseline to one-year follow-up. This cut-point has been used in several studies investigating health effects of SR [25].

Definition of smoking cessation. Abstinence from smoking was defined as self-reported point abstinence, e.g.: reported to be daily smoker at baseline and to have quit at the time of the follow-up visit-independently of smoking status at other follow-up visits. Thus, a person could be point abstinent at three-year follow-up, but smoke at five year-follow-up. Abstinence has been validated (serum cotinine $<20 \mathrm{ng} / \mathrm{ml}$ ) in the intervention groups, but not in the control group. For details: [26].

Questionnaires. All subjects completed comprehensive self-report questionnaires. Characteristics of the study population included self-reported socio-demographic measures, smoking-related measures, and measures of lifestyle and health.

Socioeconomic status was defined by length of vocational training/higher education, after finishing basic school education (e.g. unskilled worker $=0$ years, green keeper assistant $=1 \frac{1}{2}$ year, carpenter $=3 \frac{1}{2}$ years, teacher $=4$ years, medical doctor $=6$ years). Categories: One year or less, two to three years, four years or more.

Dietary quality score: a three-class variable was generated from a 52-item food frequency questionnaire (reference period: one week), based on intake of four food-groups/nutrients (fish, vegetable, fruit and fat). The score has been validated [27]. Categories: healthy, acceptable and unhealthy diet. 
Physical activity was based on self-reported leisure time physical activities. Categories: mainly sedentary, moderate activity, regular sport/exercise, athletic training or participation in competitive sports. The question was developed by Saltin B. [28] and has later been validated in a population-based study [29].

Alcohol consumption was self-reported as mean consumption of units of beer/strong beer, wine and spirits per week. "Recommended" = less than 15 units of alcohol weekly for women, and 22 units for men.

Body mass index (BMI) was calculated as $\mathrm{kg} / \mathrm{m}^{2}$.

Health related quality of life was measured by version 1 of the Short Form 12 (SF-12), which is a generic measure [30], and a valid, practical and reliable alternative to the 36-item Short Form 36 (SF-36). Two scales are created, one reflecting the mental functioning and the other the physical functioning. Higher scores indicate better health. The summary scores were calculated using the Medical Outcomes Study scoring system [30,31].

Chronic cough: self-reported cough of at least three months duration in the last two years.

\section{Statistical Analyses}

All data processing was done with the SPSS 19.0 software (SPSS Inc., Chicago, IL, USA). Pearson ChiSquare test and One-way ANOVA were used to look at baseline differences between reducers and non-reducers at one-year follow-up. Tobacco consumption and age showed clear heteroscedasticity and was analysed by
Independent-Samples Man-Whitney U test.

To investigate whether SR at one-year follow-up was associated with future smoking cessation we used logistic regression analyses. Point abstinence at three and five-year follow-up was outcome and SR of $50 \%$ or more at one-year follow-up was the independent variable. We adjusted for 1) factors we know influence smoking cessation: intervention or control group, sex, age at smoking debut, socio economic status, motivation to quit and tobacco consumption at baseline and 2) factors that significantly differed between reducers and non-reducers in this study: age, diet and number of previous quit attempts. In order to test whether there was a different effect of SR on smoking cessation by intervention or control group, we tested the interaction between group and SR. The model was controlled by the Hosmer-Lemeshow goodness-of-fit test.

\section{RESULTS}

At baseline reducers had a significantly healthier diet, more previous quit attempts and they were older than non-reducers (Table 1).

Tobacco consumption was four grams higher in reducers than non-reducers, but this was not statistically significant. Socio-demographic measures, other smoking related measures, self-reported physical and mental health and other measures of lifestyle did not differ significantly in reducers and non-reducers.

About twice as many reducers as non-reducers reported

Table 1. Baseline characteristics of reducers (tobacco consumption reduced by at $50 \%$ or more compared with baseline) and nonreducers at one-year follow-up.

\begin{tabular}{|c|c|c|c|c|c|}
\hline & \multicolumn{3}{|c|}{ Reducers } & \multirow[t]{2}{*}{ Non-reducers } & \multirow[t]{2}{*}{$\mathrm{p}$} \\
\hline & $\mathrm{N}$ & & $\mathrm{N}$ & & \\
\hline $\operatorname{Sex}=\operatorname{men}(\%)$ & 112 & 52.7 & 1863 & 50.6 & 0.672 \\
\hline Age (mean, SD) & 112 & $48.71( \pm 7.1)$ & 1863 & $46.83( \pm 8.6)$ & 0.043 \\
\hline Socioeconomic status $=$ high $(\%)$ & 104 & 47.1 & 1720 & 38.1 & 0.120 \\
\hline Occupational status $=$ employed $(\%)$ & 110 & 83.6 & 1850 & 80.6 & 0.432 \\
\hline Living with partner $=$ yes $(\%)$ & 111 & 73.9 & 1832 & 78.3 & 0.271 \\
\hline Age at smoking debut (mean, $\pm \mathrm{SD}$ ) & 108 & $17.60( \pm 4.7)$ & 1848 & $16.99( \pm 4.2)$ & 0.146 \\
\hline Tobacco consumption (mean, \pm SD) & 112 & $21.67( \pm 16.0)$ & 1863 & $17.53( \pm 8.0)$ & 0.065 \\
\hline Number of previous quit attempts (mean, \pm SD) & 102 & $5.34( \pm 15.5)$ & 1787 & $2.50( \pm 5.8)$ & 0.027 \\
\hline Diet $=$ unhealthy $(\%)$ & 105 & 16.2 & 1784 & 27.5 & 0.004 \\
\hline Alcohol consumption $=$ higher than recommended $(\%)$ & 110 & 20.9 & 1787 & 23.7 & 0.607 \\
\hline Physical activity in leisure time $=$ sedentary $(\%)$ & 110 & 27.3 & 1818 & 27.8 & 0.488 \\
\hline Chronic cough $^{\mathrm{a} .}=$ yes $(\%)$ & 89 & 14.6 & 997 & 12.1 & 0.497 \\
\hline Body mass index (mean, $\pm \mathrm{SD}$ ) & 112 & $25.75( \pm 3.6)$ & 1854 & $25.33( \pm 4.3)$ & 0.306 \\
\hline Self-rated health $=$ fair/poor $(\%)$ & 112 & 9.8 & 1853 & 12.8 & 0.297 \\
\hline Health related quality of life (SF-12) physical score & 102 & $49.82( \pm 7.7)$ & 1713 & $50.77( \pm 7.9)$ & 0.236 \\
\hline Health related quality of life (SF-12) mental score & 102 & $52.12( \pm 7.8)$ & 1713 & $51.09( \pm 9.2)$ & 0.266 \\
\hline
\end{tabular}

a. only answered by persons who reported cough. 
at both three and five-year follow-up that they had been smoke-free within the last 12 months and/or had tried to quit since baseline; the differences were significant $(\mathrm{p}<$ 0.05) (Figure 1).

The mean number of quit attempts from baseline to five-year follow-up was $2.52(\mathrm{SD} \pm 5.1)$ in non-reducers and $3.79(\mathrm{SD} \pm 6.4)$ in reducers. The difference was not statistically significant $(\mathrm{p}=0.148)$.

In adjusted logistic regression analyses we found no association between reduced tobacco consumption at one-year follow-up and being point abstinent at three- or five-year follow-up. Actually, reducers had slightly lower probability of having quit at three year follow-up than non-reducers, although the difference was not statistically significant (Table 2).

We found no interaction between group and reduced tobacco consumption, indicating that the effect of reduction on long-term abstinence was the same in the intervention group as the control group.

Of those who had reduced at one-year follow-up and attended three-year and five-year follow-up 19.6\% ( $=$ $22)$ and $20.5 \%(\mathrm{~N}=23)$, respectively, had still reduced their tobacco consumption by $50 \%$ or more.

\section{DISCUSSION}

In this population-based cohort we found that successful reduction of tobacco consumption was associated with higher incidence of quit attempts but did not increase abstinence from smoking in the future. Only one out of five reducers could keep the low tobacco consumption on long-term. Reducers had a significantly healthier diet, higher age and more previous quit at- tempts at baseline than non-reducers.

Smoking reduction has been a hot topic in the last decade. Before implementing this new tobacco control strategy world-wide we need following evidence: 1) Is SR feasible, also on a population-based level? 2) Has SR a health benefit? and 3) Does SR increase future smoking cessation or at least not undermine it? This paper contributes to the third answer. Several studies have reported a significantly positive association between SR and future smoking cessation [7,11-14,17-20]. Others, including our study, found no significant effect of SR on future smoking cessation [3-6,8,9,15].

An important explanation for the different conclusions may be the different definition of smoking reduction. Some have looked at levels of reduction $[8,14,18]$, others have defined reduction as a change from daily to non-daily smoking [16], reduction to below 15 cigarettes per day [19] or any reduction in tobacco consumption $[3,6,17]$. Different duration of follow-up may also have an influence. The shortest follow-up has been four months, the longest nine years [14]. Other methodological differences may be of importance. Several studies testing the efficacy of NRT to achieve SR investigated future abstinence. Five out of six of these studies compared smokers trying to reduce with NRT with smokers trying to reduce with placebo/without NRT and can not answer the research question $[4,7,9,11,12]$. Only one of the studies compared reducers with non reducers [13]. Self-selection may also play a role as many of the trials offered free NRT [3,4,7-9,11-13,17]. Also, many studies did not include confounders [3,4,6-8,10,12,13,15]. In our study, in unadjusted analyses, we found that SR actually

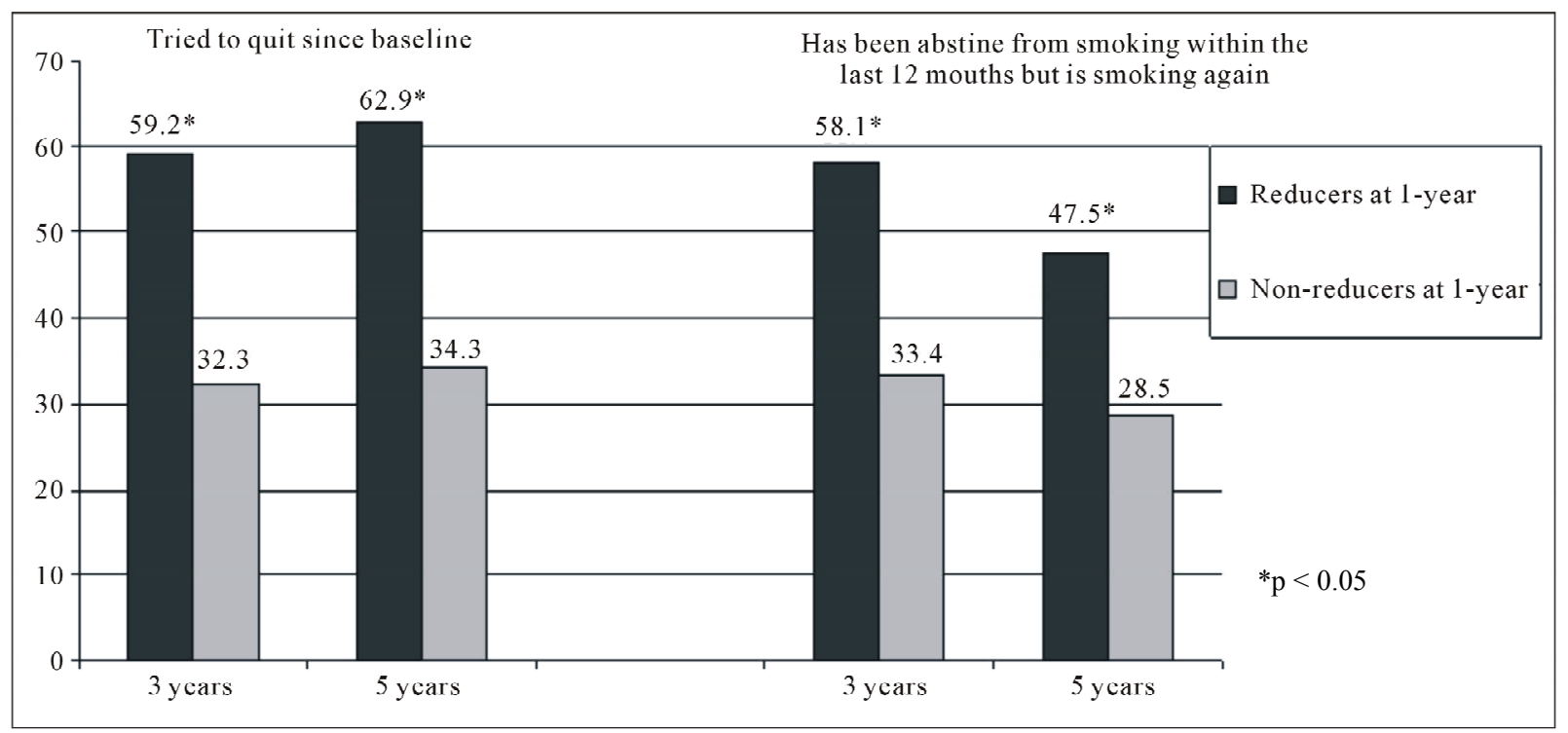

Figure 1. Percentage of daily smokers reporting quit attempts. Reducers (daily smokers who had reduced by $50 \%$ or more from baseline to 1 year follow-up) compared with non-reducers. 
Table 2. Probability of long-term abstinence from smoking in reducers (tobacco consumption reduced by at $50 \%$ or more compared with baseline) and non-reducers. $\mathrm{N}=1593$.

\begin{tabular}{ccccc}
\hline & $\begin{array}{c}\text { Abstinent from } \\
\text { smoking at 3-year } \\
\text { follow-up }\end{array}$ & \multicolumn{2}{c}{$\begin{array}{c}\text { Abstinent from } \\
\text { smoking at 5-year } \\
\text { follow-up }\end{array}$} \\
\hline & OR & $95 \% \mathrm{CI}$ & OR & $95 \% \mathrm{CI}$ \\
Non-reducers & 1 & & 1 & \\
Reducers & & & & \\
Unadjusted & 0.54 & $0.28-1.04$ & 0.97 & $0.52-1.82$ \\
Adjusted $^{\mathrm{a}}$ & 0.57 & $0.28-1.15$ & 1.08 & $0.56-2.09$ \\
\hline
\end{tabular}

${ }^{a}$ Adjusted for group, age, sex, age at smoking debut, motivation to quit, number of previous quit attempts, tobacco consumption, diet and socioeconomic status at baseline.

decreased the probability of abstinence at three-year follow-up.

Very important studies are those randomising smokers to reduction or no reduction/usual care $[5,10,15]$. Only one out of three of these studies showed significantly increased abstinence rates [10]. Most previous population-based studies have, in contrary to our study, found a positive association between SR and future smoking cessation [14,16,18-20]. However, three of these studies were on selected smokers; one study was in older smokers [18], one in young women [16], one in twins [14]. Additionally, one population-based study used recalled tobacco consumption one year before study start, with high risk of recall bias [19] and another was old, looking at changes in consumption from 1975 to 1981 to predict abstinence [14].

A review from 2006 stated that SR increases the probability of future cessation [32], but in our opinion, this should be modified to: no studies have shown that SR undermines future cessation. Another general finding is that prospective studies have shown that smoking reduction has to be substantial to show an effect on future cessation $[10,14,16,18-20]$.

Previous studies have reported that reducers were characterised by high tobacco consumption, and bad health [33-35]. In this study the mean tobacco consumption was (non-significantly) higher, about four grams more per day, in reducers than in non-reducers, but reducers in our study did not report worse health than non-reducers. Two factors could explain this difference in health. Firstly, time of studies. E.g. the large study by Godtfredsen et al. was performed on changes in smoking patterns in the 1970ies/early 1980ies. At that time tobacco reduction was not introduced as a strategy in tobacco control and smoking was unrestricted everywhere. Therefore, smoking reduction was probably a choice for those who had bad health/smoking-related symptoms and were unable to smoke as much as previously. Secondly, smokers unable or unwilling to quit were encouraged to reduce in the Inter99 intervention groups, even young smokers without any symptoms. Overall reducers in our study seemed to live a little healthier and to be a little better educated. This gives us a picture of heavy-smokers with many quit attempts, trying to live healthy, but being unable to quit.

The finding that reducers showed a significant increase in 'being smoke-free within the past 12 months' and 'had tried to quit', but not an increase in pointprevalent abstinence could seem contradictory. Our interpretation is, that reducers do wish to and do try to quit, but their quit attempts fail. The many quit attempts after SR is good news, as many have feared that SR would be pretext for doing nothing, being content with the reduced level of smoking.

Weaknesses and limitations. The major weakness of our study is the lack of validation of the tobacco consumption. In the smoking cessation part of this study the misclassification rate of the quitters was $16 \%$ [36]. Thus, it is also probable that tobacco consumption was underreported. Also, the total sample of 112 reducers is very small and is likely underpowered to show much differences between groups in subsequent cessation.

The definition of 'successful reduction' can be discussed. We could as well have defined reduction as smoking 10 cigarettes less, or below 15 grams of tobacco. Our definition of reduction was chosen partly because many other studies have used this definition $[5,7,11,12,15,37]$ and partly because smokers who reduce their tobacco consumption compensate by inhaling deeper. Therefore, reduction has to be substantial to have any health benefit [25]. One of the problems with our definition is that light smokers can halve their tobacco consumption without reducing very much.

We must also consider the influence of the SR intervention. In this paper we included participants from both the intervention groups and the control group, but most of the reducers were from the intervention group. As only $2 \%$ of the smokers in high intensity intervention group A accepted and attended the group-based SR intervention we assumed that the influence of the SR intervention was minimal. We found no interaction between group and effect of SR on smoking cessation, supporting that the effect of SR was the same in the intervention and the control group.

Finally, the relatively low participation rate may have caused selection bias. The study population was an unselected random sample of a general population, but in a baseline publication we found that participation rate was higher in younger women than in younger men, and it increased with increasing age until 55 years of age after 
which it declined. The participants in the intervention group did not differ from those in the control group, regarding former admissions for all causes, IHD, CVD, and diabetes [22]. Residual confounding can not be excluded and unknown confounding should always be a matter of concern. Drop-out may also have caused selection bias, but we had information on about three out of four baseline smokers on long term. High baseline tobacco consumption and continuous smoking was found to be associated with drop-out.

Strengths. The study is large and daily smokers were randomly included from a general population. There were no differences in tobacco related or socio-demographic measures between daily smokers in the control group and the intervention group at baseline, except a higher wish to quit in the intervention group [38]. We have included relevant confounders, used relevant statistical analyses and we have a long follow-up.

\section{CONCLUSIONS}

Our study including many smokers from a general population found no association between SR and future smoking cessation at three- and five-year follow-up. No studies so far have reported that SR undermines smoking cessation, but it is still controversial whether SR significantly promotes future smoking cessation.

\section{ACKNOWLEDGEMENTS}

We thank the whole Inter99-staff and all persons participating in the study. Also, we thank the funding providers. Both those who funded this paper and those who funded the Inter99 study: Helsefonden; Danish Medical Research Council; The Danish Centre for Evaluation and Health Technology Assessment; Novo Nordisk; Copenhagen County; Danish Heart Foundation; The Danish Pharmaceutical Association; Augustinus Foundation; Becket Foundation; Ib Henriksens Foundation.

The study was initiated by Torben Jorgensen, Knut Borch-Johnsen, Troels Thomsen and Hans Ibsen. The Steering Committee of the Inter99 study: Professor D.M.Sci. Torben Jorgensen (principal investigator), Professor D.M.Sci., Knut Borch-Johnsen (principal investigator on the diabetes part) and Ph.D. MPH Charlotta Pisinger.

\section{REFERENCES}

[1] Peto, R., Lopez, A.D., Boreham, J., Thun, M., Heath, C. Jr., Doll, R. (1996) Mortality from smoking worldwide. British Medical Bulletin, 52, 12-21.

[2] Boyle, P. (1997) Cancer, cigarette smoking and premature death in Europe: A review including the Recommendations of European Cancer Experts Consensus Meeting, Helsinki, October 1996. Lung Cancer, 17, 1-60. doi:10.1016/S0169-5002(97)00648-X

[3] Cropsey, K.L., Jackson, D.O., Hale, G.J., Carpenter, M.J. and Stitzer, M.L. (2011) Impact of self-initiated pre-quit smoking reduction on cessation rates: results of a clinical trial of smoking cessation among female prisoners. Addictive Behaviors, 36, 73-78. doi:10.1016/j.addbeh.2010.08.026

[4] Bolliger, C.T., Zellweger, J.P., Danielsson, T., van Biljon, X., Robidou, A., Westin, A., et al. (2000) Smoking reduction with oral nicotine inhalers: Double blind, randomised clinical trial of efficacy and safety. British Medical Journal, 321, 329-333.

doi:10.1136/bmj.321.7257.329

[5] Carpenter, M.J., Hughes, J.R. and Keely, J.P. (2003) Effect of smoking reduction on later cessation: A pilot experimental study. Nicotine and Tobacco Research, 5, 155- 162. doi:10.1080/146222003100007385

[6] Meyer, C., Rumpf, H.J., Schumann, A., Hapke, U. and John, U. (2003) Intentionally reduced smoking among untreated general population smokers: prevalence, stability, prediction of smoking behaviour change and differences between subjects choosing either reduction or abstinence. Addiction, 98, 1101-1110. doi:10.1046/j.1360-0443.2003.00475.x

[7] Wennike, P., Danielsson, T., Landfeldt, B., Westin, A. and Tonnesen, P. (2003) Smoking reduction promotes smoking cessation: Results from a double blind, randomized, placebo-controlled trial of nicotine gum with 2-year follow-up. Addiction, 98, 1395-1402. doi:10.1046/j.1360-0443.2003.00489.x

[8] Hughes, J., Lindgren, P., Connett, J. and Nides, M. (2004) Smoking reduction in the Lung Health Study. Nicotine and Tobacco Research, 6, 275-280. doi:10.1080/14622200410001676297

[9] Etter, J.F., Laszlo, E. and Perneger, T.V. (2004) Postintervention effect of nicotine replacement therapy on smoking reduction in smokers who are unwilling to quit: randomized trial. Journal of Clinical Psychopharmacology, 24, 174-179. doi:10.1097/01.jcp.0000115666.45074.d6

[10] Carpenter, M.J., Hughes, J.R., Solomon, L.J. and Callas, P.W. (2004 ) Both smoking reduction with nicotine replacement therapy and motivational advice increase future cessation among smokers unmotivated to quit. Journal of Consulting and Clinical Psychology, 72, 371-281. doi:10.1037/0022-006X.72.3.371

[11] Batra, A., Klingler, K., Landfeldt, B., Friederich, H.M., Westin, A. and Danielsson, T. (2005) Smoking reduction treatment with 4-mg nicotine gum: A double-blind, randomized, placebo-controlled study. Clinical Pharmacology \& Therapeutics, 78, 689-696. doi:10.1016/j.clpt.2005.08.019

[12] Rennard, S.I., Glover, E.D., Leischow, S., Daughton, D.M., Glover, P.N., Muramoto, M., et al. (2006) Efficacy of the nicotine inhaler in smoking reduction: A double-blind, randomized trial. Nicotine and Tobacco Research, 8, 555-564. doi:10.1080/14622200600789916

[13] Etter, J.F. and Laszlo, E. (2007) Postintervention effect of nicotine replacement therapy for smoking reduction: a randomized trial with a 5-year follow-up. Journal of Clinical Psychopharmacology, 27, 151-155. doi:10.1097/JCP.0b013e318033bd72

[14] Broms, U., Korhonen, T. and Kaprio, J. (2008) Smoking reduction predicts cessation: longitudinal evidence from 
the Finnish adult twin cohort. Nicotine and Tobacco Research, 10, 423-427.

[15] Joseph AM, Hecht SS, Murphy SE, Lando H, Carmella SG, Gross M, et al. (2008) Smoking reduction fails to improve clinical and biological markers of cardiac disease: A randomized controlled trial. Nicotine and Tobacco Research, 10, 471-481. doi:10.1080/14622200801901948

[16] McDermott, L., Dobson, A. and Owen, N. (2008) Smoking reduction and cessation among young adult women: a 7-year prospective analysis. Nicotine and Tobacco Research, 10, 1457-1466. doi:10.1080/14622200802323241

[17] Okuyemi, K.S., Thomas, J.L., Warren, J., Guo, H. and Ahluwalia, J.S. (2010) Relationship between smoking reduction and cessation among light smokers. Nicotine and Tobacco Research, 12, 1005-1010. doi:10.1093/ntr/ntq138

[18] Falba, T., Jofre-Bonet, M., Busch, S., Duchovny, N. and Sindelar, J. (2004) Reduction of quantity smoked predicts future cessation among older smokers. Addiction, 99, 93-102. doi:10.1111/j.1360-0443.2004.00574.x

[19] Farkas, A.J. (1999) When does cigarette fading increase the likelihood of future cassation? Annals of Behavioral Medicine, 21, 71-76. doi:10.1007/BF02895036

[20] Hyland, A., Levy, D.T., Rezaishiraz, H., Hughes, J.R., Bauer, J.E., Giovino, G.A., et al. (2005) Reduction in amount smoked predicts future cessation. Psychology of Addictive Behaviors, 19, 221-225. doi:10.1037/0893-164X.19.2.221

[21] Pisinger, C., Vestbo, J., Borch-Johnsen, K. and Jorgensen, T. (2005) Smoking reduction intervention in a large population-based study. The Inter99 study. Preventive Medicine, 40, 112-118. doi:10.1016/j.ypmed.2004.05.014

[22] Jorgensen, T., Borch-Johnsen, K., Thomsen, T.F., Ibsen, H., Glumer, C. and Pisinger, C. (2003) A randomized non-pharmacological intervention study for prevention of ischaemic heart disease: Baseline results Inter99. European Journal of Cardiovascular Prevention \& Rehabilitation, 10, 377-386.

doi:10.1097/01.hjr.0000096541.30533.82

[23] Homepage of the Inter99 study (2008), www.Inter99.dk

[24] Osler, M., Linneberg, A., Glumer, C. and Jorgensen, T. (2011) The cohorts at the Research Centre for Prevention and Health, formerly "The Glostrup Population Studies". International Journal of Epidemiology, 40, 602-610. doi:10.1093/ije/dyq041

[25] Pisinger, C. and Godtfredsen, N.S. (2007) Is there a health benefit of reduced tobacco consumption? A systematic review. Nicotine and Tobacco Research, 9, 631646. doi:10.1080/14622200701365327

[26] Pisinger, C. (2007) High risk strategy in smoking cessation is feasible on a population-based level. The Inter99 study. Master of Public Health, University of Copenha- gen, Copenhagen.

[27] Toft, U., Kristoffersen, L.H., Lau, C., Borch-Johnsen, K. and Jorgensen, T. (2007) The dietary quality score: Validation and association with cardiovascular risk factors: the Inter99 study. European Journal of Clinical Nutrition, 61, 270-278. doi:10.1038/sj.ejcn. 1602503

[28] Saltin, B. and Grimby, G. (1968) Physiological analysis of middle-aged and old former athletes. Comparison with still active athletes of the same ages. Circulation, 38, 1104-1115.

[29] Lochen, M.L. and Rasmussen, K. (1992) The Tromso study: Physical fitness, self reported physical activity, and their relationship to other coronary risk factors. Journal of Epidemiology and Community Health, 46, 103-107. doi:10.1136/jech.46.2.103

[30] Ware, J. Jr., Kosinski, M. and Keller, S.D. (1995) SF-12: How to Score the SF-12 Physical and Mental Health Summary Scales. The Health Institute, New England Medical Center, Boston.

[31] Bjorner, J.B., Damsgaard, M.T., Watt, T., Bech, P., Rasmussen, N.K., Modvig, J., et al. (1997) Dansk manual til SF-36. Et spørgeskema om helbredsstatus. Lif-Lægemiddelindustriforeningen, Copenhagen.

[32] Hughes, J.R. and Carpenter, M.J. (2006) Does smoking reduction increase future cessation and decrease disease risk? A qualitative review. Nicotine and Tobacco Research, 8, 739-749. doi:10.1080/14622200600789726

[33] Godtfredsen, N.S., Prescott, E., Osler, M. and Vestbo, J. (2001) Predictors of smoking reduction and cessation in a cohort of danish moderate and heavy smokers. Preventive Medicine, 33, 46-52. doi:10.1006/pmed.2001.0852

[34] Garcia, M., Fernandez, E., Schiaffino, A., Peris, M. and Borras, J.M. (2005) Smoking reduction in a populationbased cohort. Preventive Medicine, 40, 679-684. doi:10.1016/j.ypmed.2004.09.007

[35] Joseph, A.M., Bliss, R.L., Zhao, F. and Lando, H. (2005 ) Predictors of smoking reduction without formal intervention. Nicotine and Tobacco Research, 7, 277-282. doi:10.1080/14622200500056176

[36] Pisinger, C., Vestbo, J., Borch-Johnsen, K. and Jorgensen, T. (2005) Smoking cessation intervention in a large randomised population-based study. The Inter99 study. Preventive Medicine, 40, 285-292. doi:10.1016/j.ypmed.2004.06.001

[37] Godtfredsen, N.S., Prescott, E., Vestbo, J. and Osler, M. (2006) Smoking reduction and biomarkers in two longitudinal studies. Addiction, 101, 1516-1522. doi:10.1111/j.1360-0443.2006.01542.x

[38] Pisinger, C., Vestbo, J., Borch-Johnsen, K., Thomsen, T. and Jorgensen, T. (2005) Acceptance of the smoking cessation intervention in a large population-based study: the Inter99 study. Scandinavian Journal of Public Health, 33, 138-145. doi: 10.1080/14034940410028370 